IJCOM 2021 November;1(2):89-93

\title{
The Importance and Challenges of Research and Publishing in Occupational Health During COVID-19 Pandemic
}

\author{
Mikhael Yosia ${ }^{1,2,3^{*}}$, Ray Wagiu Basrowi ${ }^{2,3}$ \\ ${ }^{1}$ Medecines Sans Frontieres, Spain \\ ${ }^{2}$ Occupational Medicine Magister Program, Department of Community Medicine, Faculty of Medicine, Universitas Indonesia \\ ${ }^{3}$ The Association of Alumni of Occupational Medicine Magister Faculty of Medicine Universitas Indonesia (ILUNI MKK FKUI) \\ Corresponding address: Mikhael Yosia \\ Email: mikhael.yosia01@ui.ac.id
}

\begin{abstract}
Nearing the end of the second year of the COVID-19 pandemic, businesses and companies had decided to continue their operations and strive forwards, posing superfluous challenges to occupational health $(\mathrm{OH})$ professionals in keeping workers safe against the continuous threat of infections. The novelty of COVID-19 results in a myriad of medical questions, all of which needs to be answered promptly and reliably through medical research followed by dissemination of answer through publications. Making the knowledge accessible through publications ensures that $\mathrm{OH}$ professionals and other relevant parties can collectively develop new policies, determine preventive action, the standard of procedures and care, and administer medical procedures - all of which eases the fight against pandemics in the workplace. Despite its complications and challenges, the author hoped that $\mathrm{OH}$ professionals realized the importance of research and publishing in the fight against this pandemic. Keywords: occupational health, Occupational Health Professionals, publication, journal, COVID-19.
\end{abstract}




\section{Introduction}

COVID-19 had impacted workers and business, resulting in an unprecedented change in the workplace, working procedures, and habits in nearly all fields of works.1,2 It started with the fact that critical and essential business sectors need to continue, increasing the risk of COVID-19 exposure to workers in these fields, followed by a giant experiment in continuing life and businesses under the pretense of a "new normal." All of these warrant a significant overhaul in the business management plan; while at the same time shifting occupational health $(\mathrm{OH})$ focus on generating a safe environment that minimizes the spread of infections to ensure the continuation of worker's wellbeing and businesses throughout the pandemic.

As companies scramble to create business continuity plan that would suit the pandemic, $\mathrm{OH}$ professionals had to rapidly come up with safety protocol and procedures to ensure the safety of its workers; this includes creation and implementation of practical measures to questions such as: "What mask worker should be using?", "What happened to COVID positive workers?" and "How can disinfectant be used to clean the office?". Although many of the questions posed are related to general infection control, the novelty of COVID-19 also resulted in a knowledge gap that acts as a further blindfold to $\mathrm{OH}$ professionals, resulting in unreliable health policies that affect the lives of countless workers. ${ }^{3}$

To tackle the conundrum above, most $\mathrm{OH}$ professionals turn to journals or policies from established health and occupational institutions (WHO - World Health Organization, ILO - International Labour Organization, CDC - Center for Disease Control, etc.); however, some still relied on mere hearsay, gut feelings, or common practices without proven evidence. ${ }^{4}$ The problem is further complicated because $\mathrm{OH}$ professionals need to fit national or headquarters policies into their company daily's activity - which at times requires extensive adaptation according to the actual condition at the field. The old issue of limited research in niche fields, such as $\mathrm{OH}$, had become evident and truly grown to become a substantial problem in the fight against this pandemic. The rarity of available $\mathrm{OH}$ practitioners (and even rarer $\mathrm{OH}$ researcher) may be an issue; but a lack of knowledge, initiatives, and incentives on writing and publishing observations, report and unique health cases as research studies poses a bigger threat that needs to be addressed.

How the pandemic changes publications in $\mathrm{OH}$ and low awareness to search for and publish evidence surrounding the pandemic is an issue that has been sparsely discussed. This paper aims to break down the advantages and importance of publishing in occupational medicine during the pandemic while addressing publications' challenges and how to tackle them.

\section{Medical questions need to be answered (promptly and reliably)}

The novelty and significant impact that COVID-19 had on every aspect of human life deemed it necessary to concentrate many of our resources tackling the disease. Many of the questions surrounding the virus (and its subsequent variant) remained unanswered, but medical research had aggressively strived forward to untangle the mess that is this pandemic - with virology research increases from $2 \%$ to $10-20 \%$ out of all biomedical research after the start of the pandemic and massive influx of medical publications. ${ }^{5,6}$ Information from labbased research looking at the basic fundamental science of COVID-19 will eventually trickle down to clinically relevant research such as the development of vaccines and easier diagnostic methods.

As of writing this paper, there is no information regarding the trend of $\mathrm{OH}$ research during the pandemic globally or within Indonesia. However, research interest from $\mathrm{OH}$ professionals regarding the pandemic is high with $42 \%$ of Universitas Indonesia Magister Kedokteran Kerja (MKK) candidates opt to do a COVID-19 related topic in 2021 (Table 1), representing the fact that numerous pandemic related questions and research topic is available in the workplace; given the correct guidance and opportunities, these questions can develop to a research publication.

On another note, it is surprisingly common that $\mathrm{OH}$ Professionals in Indonesia adapt (with or without necessary modifications) foreign policies and apply them to their workplace. Recommendations from ILO, WHO, CDC, or large foreign companies are useful to address major issues surrounding the pandemic, yet details inside the policies could also be unrealistic and impractical. Recommendations and policies from these large institutions are reliable because they are made upon sound research conducted (mostly) in the country where it is based (e.g., CDC in the US). When these policies are 
Table 1. Ongoing COVID-19 related research titles from Universitas Indonesia MKK candidate thesis in 2021

\begin{tabular}{|c|c|c|}
\hline Research title ${ }^{a}$ & Research design & Type of industries \\
\hline $\begin{array}{l}\text { The effect of dual roles on work stress in female workers during the } \\
\text { COVID-19 pandemic }\end{array}$ & Cross-sectional & Government \\
\hline Analysis of work fatigue on geothermal workers during the pandemic & Cross-sectional & Energy (Geothermal) \\
\hline $\begin{array}{l}\text { The relationship between dehydration and the use of personal protective } \\
\text { equipment for health workers }\end{array}$ & Cross-sectional & Healthcare \\
\hline $\begin{array}{l}\text { Analysis of work fatigue with long work rotation on offshore oil and gas } \\
\text { platform workers during the pandemic }\end{array}$ & Cross-sectional & Energy (Oil and gas) \\
\hline $\begin{array}{l}\text { The relationship between the implementation of the covid-19 prevention and } \\
\text { control protocol policy in public facilities with the compliance of workers and } \\
\text { facility users in twelve provinces in Indonesia }\end{array}$ & Cross-sectional & Public services \\
\hline $\begin{array}{l}\text { Correlation between work shift and fatigue among general practitioners in } \\
\text { Bekasi COVID-19 referral hospital using IFRC (Industrial Fatigue Research } \\
\text { Committee) questionnaire }\end{array}$ & Cross-sectional & Healthcare \\
\hline $\begin{array}{l}\text { Analysis of trends in stress levels and blood pressure before and during the } \\
\text { pandemic in workers at a construction equipment production company }\end{array}$ & $\begin{array}{l}\text { Retrospective } \\
\text { cohort }\end{array}$ & Construction \\
\hline $\begin{array}{l}\text { Validity and reliability of the Fear of COVID-19 Scale (FCV-19) for } \\
\text { Indonesian health workers who treat COVID-19 patients }\end{array}$ & Cross-sectional & Healthcare \\
\hline $\begin{array}{l}\text { Assessment on the relationship between occupational factors and other factors } \\
\text { with the increasing incidence of depression on health workers using the PHQ- } \\
9 \text { screening during the COVID-19 pandemic }\end{array}$ & Cross-sectional & Healthcare \\
\hline $\begin{array}{l}\text { Analysis of computer vision syndrome issues on workers during the } \\
\text { COVID-19 pandemic }\end{array}$ & Cross-sectional & Finance (Bank) \\
\hline $\begin{array}{l}\text { Trends between vaccination and quantitative Anti-SARS-CoV-2 serology } \\
\text { results and its affecting factors in COVID-19 survivors and non-survivors }\end{array}$ & Prospective cohort & Healthcare \\
\hline $\begin{array}{l}\text { Fear of COVID-19 Scale (FCV-19) in hospitality workers in COVID-19 } \\
\text { isolation hotels }\end{array}$ & Cross-sectional & Hospitality (Hotel) \\
\hline $\begin{array}{l}\text { The relationship of hydration status to the incidence of work fatigue in health } \\
\text { workers during COVID-19 pandemic at health facilities in Tangerang }\end{array}$ & Cross-sectional & Healthcare \\
\hline $\begin{array}{l}\text { Analysis of the relationship between job satisfaction and nurse performance in } \\
\text { the COVID-19 pandemic }\end{array}$ & Cross-sectional & Healthcare \\
\hline
\end{tabular}

adapted in an $\mathrm{OH}$ setting in Indonesia, the modification are sometimes based upon individual judgments without any evidence, resulting in a lackluster policy that needs to be changed and modified numerous times.

The problem above is caused by the fact that there is not enough research conducted in the Indonesian setting that can be used as a base for policymaking, thus taking us back to the main point, that medical questions need to be answered reliably through sound, well-designed research. There are only so many adaptations that we can take from research conducted in a vastly different setting. Answering these medical questions would not only benefit $\mathrm{OH}$ scholars, but it would also help avoid unnecessary burdens to workers and companies due to unreliable policies.

\section{Publishing an occupational health research}

With no shortage in research topics and abundant chances to achieve novelty, $\mathrm{OH}$ research should have 
been a prime real estate for those wanting to increase their academic research publications. Data are always readily available to be analyzed in $\mathrm{OH}$; companies and industries often had a reliable database that could be extracted and analyzed. 7 Do realize that there are always "unofficial researches" in $\mathrm{OH}$, such as internal investigations of workers' health in a company, assessment of health and safety policies, hazard and risk identification, all of which carry valuable clinical information but are rarely published in an academic journal. Albeit these investigations are useful, there will be no immediate transfer of knowledge to other $\mathrm{OH}$ practitioners without publications, and the benefits encompass in all its findings would not find their way to the general public. Publishing your work also allows for a feedback process through peer-review and revision of the manuscript, allowing for objective external analysis for our work, finding "cracks" that missed the researcher's perspective. ${ }^{8}$ This feedback mechanism is important to ensure that the quality of research is kept at the highest standard.

Obvious legal predicaments surround the publication of research involving the company's data, making it unattractive for aspiring $\mathrm{OH}$ researchers, but it is not entirely impossible. Nevertheless, questionable conduct such as fraud, fabrications, and data manipulation should not be a shortcut to gain a company's approval in publishing a research study. Professional and ethical research conduct followed by good communication to the management that the research will bring benefit to advancement in health care and the company's reputation would surely help gain permissions for publications.

On the other side of the coin, nowadays, especially in Indonesia, there is significant growth of reputable publishers specializing in $\mathrm{OH}$ with editors and reviewers posing significant $\mathrm{OH}$ clinical and research backgrounds. This development should help ease the challenge of getting $\mathrm{OH}$ research published. Having a dedicated $\mathrm{OH}$ journal in Indonesia is vital, as it would allow rapid dissemination and source of database for $\mathrm{OH}$ knowledge. ${ }^{9}$ Undergraduate or master students who had painstakingly finished their thesis are advised to publish their work as a manuscript; this may act as a starting step for aspiring researchers while at the same time help dissemination of knowledge to the greater public - as it would allow papers to be indexed in a public domain instead of only the faculty's database.

In concurrence with previous points, publishing $\mathrm{OH}$ research had become especially important in this pandemic. In practical notes; $\mathrm{OH}$ publications related to the pandemic allows professionals to determine the efficacy of health policies and procedures, spotting new possible risk and hazards in workers, and comparing one intervention to others. Dissemination of these pieces of knowledge may prevent redundancies in using inefficient intervention, policies, or procedures and at the same time help prevents possible health issues that may arise in workers during the pandemic. Adding on to all the previous points, $\mathrm{OH}$ professionals are obliged to keep up their professional performance by collecting credit points through their professional organization; this includes updating their knowledge and writing scientific manuscripts. Publishing will allow both researcher and readers to better their $\mathrm{OH}$ care - it is truly for the greater good.

\section{Finding the right sources to answer your occupational health questions}

In terms of daily clinical care in the hospital and in the field of $\mathrm{OH}$, it is understandable that $\mathrm{OH}$ professionals would opt for the easy way to answer questions, typing it in your web search engine and clicking on the first article that appears. This is also true in terms of $\mathrm{OH}$ professionals, yet the combination of scarce reliable research and superficial search of information may become a breeding ground for trouble.

While publishing is important, the search for knowledge go both ways, a give and take process. $\mathrm{OH}$ professionals with limited knowledge of the publishing world would not be familiar with the search for a reliable evidence-based answer. The quality of answer depends on how good the question is. The capability to utilize $\mathrm{MeSH}$ terms, Boolean search, journal database and indexing (GoogleScholar, PubMed, Scopus, etc) may come naturally to those familiar with publishing research. Other technical capabilities such as judging the reputation of journals based on their Scientific Journal Ranking (SJR) and indexing would also be useful in determining the reliability of a publication. Publishing is by no means the only way to learn the proper methods of searching for evidence online, but it surely would help ease familiarize $\mathrm{OH}$ professionals to the search and judgement process.

\section{Conclusion}

The novelty and sheer impact of COVID-19 gave $\mathrm{OH}$ 
professionals new questions and challenges in conducting their work in the field, creating new policies, determining the standard of procedures and care, and administering medical procedures. Despite all its complications and difficulties, research and publications are still a reliable means to answer medical questions and disseminate knowledge among $\mathrm{OH}$ professionals. In retrospect, these points would surely apply to other medical fields struggling to combat the current global pandemic.

\section{References}

1. de Lucas Ancillo A, del Val Núñez MT, Gavrila SG. Workplace change within the COVID-19 context: a grounded theory approach. Econ Res Istraz . 2021;34(1):2297-316.

2. Boland B, Smet A De, Palter R, Sanghvi A. Reimagining the office and work life after COVID-19. McKinsey Co.
2020;(June):1-5.

3. Burdorf A, Porru F, Rugulies R. The COVID-19 (Coronavirus) pandemic: Consequences for occupational health. Vol. 46, Scandinavian Journal of Work, Environment and Health. 2020. p. 229-30.

4. Kodadek LM, Berger JC, Haut ER. Guidance vs. guidelines: the role of evidence-based medicine in the COVID-19 pandemic. J Patient Saf Risk Manag. 2020;25(6):216-8.

5. Fauci AS, Lane HC, Redfield RR. Covid-19 - Navigating the Uncharted. N Engl J Med. 2020;382(13):1268-9.

6. Harper L, Kalfa N, Beckers GMA, Kaefer M, NieuwhofLeppink AJ, Fossum M, et al. The impact of COVID-19 on research. J Pediatr Urol. 2020;16(5):715-6.

7. Use of Archival Data in Occupational Health Psychology Research. In: Research Methods in Occupational Health Psychology. 2020. p. 314-46.

8. Filler G, Nagra R. Why Should We Publish? In: Becoming a Successful Scholar. 2019. p. 7-11.

9. Basrowi RW. The Importance of Journal Publication in Community and Occupational Medicine in Indonesia. Indones J Community Occup Med. 2021;1(1):1-2. 